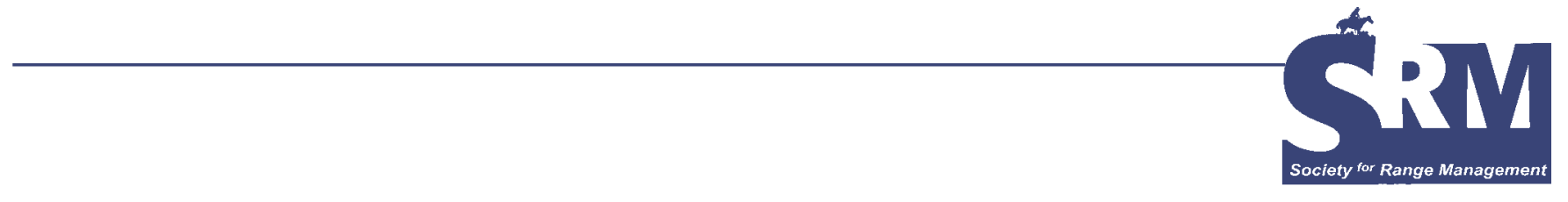

\title{
Climate Change Impacts on South American Rangelands
}

\section{By Laura Yahdjian and Osvaldo E. Sala}

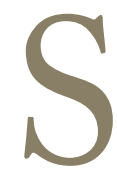

outh America is highly heterogeneous in terms of climate, ecosystems, human population distribution, and cultural traditions. Rangelands are located within regions with climatic conditions from arid to subhumid, and with mean annual precipitation ranges from approximately 150 to $1500 \mathrm{~mm}$ (6-60 inches). The boundaries of these regions are subject to modification by local soil conditions, evaporative demands, elevation, and topography. Within South America, rangelands cover 33\% of the total land area (Fig. 1), and include grasslands, shrublands, savannas, and hot and cold deserts, but exclude hyperarid deserts. ${ }^{1}$ In terms of vegetation, rangeland ecosystems of South America have an important herbaceous component, and woody vegetation can range from scattered dwarf shrubs to an almost continuous canopy of small-stature trees. This coexistence of multiple life forms occurs because plants access soil resources differently. Trees, with deeper and more extensive root systems, are able to access deeper soil moisture and nutrients; grasses, with fine, intensive root systems, are better able to exploit resources in the upper soil layers. Fire and flooding play important roles in maintaining the balance between herbaceous and woody vegetation. Frequent flooding leads to open grasslands, whereas betterdrained areas support savanna species or woodland vegetation. Large grazing mammals, mainly livestock, have a pronounced effect upon the vertical/partitioned structure of savanna grasslands. The herbaceous layer in rangelands with greater rainfall is composed of both $\mathrm{C}_{3}$ and $\mathrm{C}_{4}$ species, which typically have different growth requirements; $\mathrm{C}_{3}$ species achieve maximum productivity in the cooler, early spring, whereas $\mathrm{C}_{4}$ species have maximum productivity in the warmer late spring or early summer. Rangeland in cold climates of the southern South America is populated by $\mathrm{C}_{3}$ species.
South American rangelands include the Patagonian Steppe, the Monte, the Pampas, grass and savanna woodland known as "Llanos" or "Cerrado," the open dry thorny woodlands called "Chaco," and the dry thorn scrub named "Caatinga" (Fig. 1). Rangelands are associated with climates with pronounced dry seasons, high fire frequencies, and highly variable (and unusual) soil properties. Over much of South America, change in the intensity and location of tropical thunderstorms is the fundamental driver of climate, but weather patterns other than tropical storms also play a role through the year in southern South America. The Andes serve as a continental barrier along the Pacific coast of South America and the Amazon Basin has the distinction of being the world's largest rainforest. These unique geographical features play a crucial role in shaping the climate of South America. A warm season precipitation maximum, associated with the South American Monsoon System, dominates the mean seasonal cycle of precipitation in tropical and subtropical latitudes. In temperate latitudes, precipitation is typically more uniform during the year, whereas in the Patagonian region, a Mediterranean climate is characteristic with a cool-season precipitation maximum.

Temperature and precipitation are the main climate variables controlling species composition. However, variation in rangeland productivity is directly related with highly variable amounts and seasonal distribution of precipitation, and only secondarily controlled by other climatic variables. Primary productivity, the rate at which plants accumulate biomass, varies linearly along the arid to subhumid rangelands (150$1500 \mathrm{~mm}$ or 6-60 inches, mean annual rainfall), according to a model constructed using 14 South American ecosystems. ${ }^{2}$ This relationship between primary productivity and precipitation in arid to subhumid ecosystems is widely similar across 


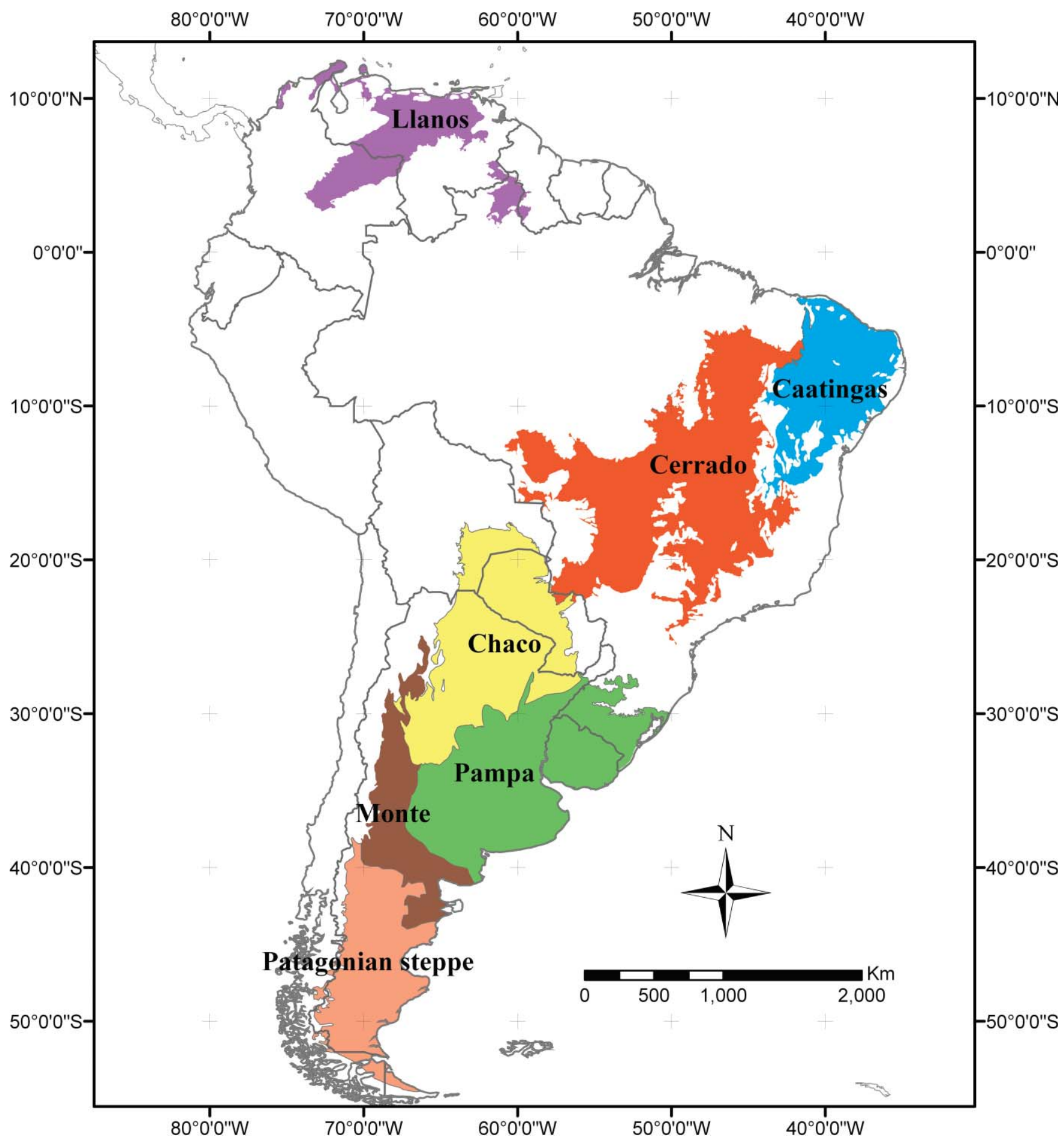

Figure 1. Map of South America Rangelands distributions and extension. Regions occupied by extensive arid to subhumid ecosystems where rangeland is one of the main productivity activities are shown with colors. Redrawn from Olson et al. ${ }^{10}$ and Eva et al. ${ }^{11}$

all geographic regions with an increment between one-half and three-fourths of a gram of production per square meter annually for each millimeter of precipitation.

Also, a number of ecosystem properties of the herbivore trophic level (biomass, consumption, and productivity) are significantly correlated with primary productivity in South American terrestrial ecosystems ranging from deserts to tropical forests. ${ }^{3}$ In accordance with this pattern, livestock biomass increases linearly with primary productivity across 67 agricultural sites in Argentina. ${ }^{4}$ Interestingly, the biomass of livestock supported per unit of primary production is about an order of magnitude above the level of natural herbivores, which indicates that agricultural management practices such as dietary supplementation, animal 
husbandry, and/or elimination of predators significantly increases the production of these ecosystems. ${ }^{4}$

Nutrient availability can also constrain primary production and livestock biomass in South American rangelands. Savanna vegetation of the neotropics is often associated with unusually infertile soils. On the other extreme, Argentinean Pampas rangelands occur on soils that are among the Earth's most fertile. Experimental fertilization with $\mathrm{N}$ and $\mathrm{P}$ in Venezuelan llanos improved plant growth and production. Grassland fertilization experiments throughout Argentina encompassing climates from subtropical to temperate also showed increases in plant growth with better responses to $\mathrm{P}$ fertilization than $\mathrm{N}$ fertilization, in some cases. Even in the arid Patagonian steppe (mean annual precipitation of less than $200 \mathrm{~mm}$ or 8 inches), nitrogen additions produced significant biomass production increases in the native grasses (L. Yahdjian and O. E. Sala, unpublished data, 2008). In another study, when all sites were combined, the large variability in soils and climates masked a clear relationship between yield and response to fertilization, highlighting that soil features vary at scales smaller than the regional patterns. ${ }^{2}$ This held true even when there was a linear increase in yield corresponding to $\mathrm{N}$ and $\mathrm{P}$ fertilization rates.

\section{Human Uses: Rangeland Activities and Importance in the Economy}

South American rangelands sustain pastoralist activities, subsistence farming, and commercial ranching, and are a key factor in the economy of many countries (e.g., Brazil, Argentina, and Uruguay). There are approximately 570 million animal units of livestock in the subcontinent, and over $80 \%$ of them graze rangelands. ${ }^{5}$

The relationship between primary productivity and livestock biomass described earlier was accompanied by an observed pattern of change in average body size of major herbivores, which in South America are represented by livestock. A reduction in the proportion of sheep, compared to cattle, present in livestock herds with increasing aboveground net primary production was evident across 67 locations in Argentina. ${ }^{4}$ The proportion of sheep varies from near $100 \%$ at the lowest primary productivity levels in Patagonia where less than $200 \mathrm{~mm}$ (8 inches) of precipitation falls annually to near zero in the areas where the highest productivity is achieved in the subtropical regions with annual precipitation levels near $1500 \mathrm{~mm}$ (60 inches). ${ }^{4}$ Sheep production is the main economic activity in the Patagonian steppe region and is based on rangeland grazing. There are approximately 15 million sheep present, with a production of 50,000 tons of wool yearly. In 2002, mutton and sheep wool exports from the Patagonian region were worth US\$607 million.

Projected Climate Change for South America Warming for South American rangelands is likely to be similar to the expected global warming for southern South
America, and higher than the predicted global warming in Northern South America. ${ }^{5}$ The mean warming for South America, projected to the end of the century by several climate models, ranges from $1-4^{\circ} \mathrm{C}\left(1.9-7.2^{\circ} \mathrm{F}\right)$ or $2-6^{\circ} \mathrm{C}$ (3.6-10.8 $\left.8^{\circ} \mathrm{F}\right)$, depending on scenario assumptions for each model. For 2020, temperature changes range from a warming of $0.4^{\circ} \mathrm{C}$ to $1.8^{\circ} \mathrm{C}\left(0.7-3.25^{\circ} \mathrm{F}\right)$, and for 2080 of 1.0 $4.5^{\circ} \mathrm{C}\left(1.8^{-8}-1^{\circ} \mathrm{F}\right)$. The highest values of warming are projected to occur over tropical South America and, generally, in the most continental regions such as inner Amazonia (Fig. 2). However, all of South America is very likely to warm during this century. Seasonal variations in warming are relatively modest. The projected warming trends indicate larger increases will occur in the summers (DecemberFebruary), rather than during the winters (June-August), except for central Amazonia (Fig. 2).

Most projections using general circulation models highlight the complexity of precipitation patterns..$^{5}$ For tropical South America, projections range from a reduction of $20-40 \%$ to an increase of $5-10 \%$ by 2080 . Uncertainty is even larger for southern South America during both the winter and summer seasons, although the predicted percentage change in precipitation is somewhat smaller than that for tropical South America (Fig. 2). Annual precipitation is likely to decrease in the southern Andes with relative precipitation changes being largest in summer (Fig. 2). Changes in atmospheric circulation might induce large changes in local variability of precipitation in the mountain areas. Precipitation is likely to increase in Tierra del Fuego during the winter and in the Pampas region during the summer. It is uncertain how yearly and seasonal rainfall will change over northern South America. In some regions, there is agreement among rainfall simulations predicting rainfall increases in Ecuador and Northern Peru, and decreases at the northern tip of the continent and in southern portions of northeastern Brazil (Fig. 2). The seasonal cycle varies, especially over the Amazon Basin where monsoon precipitation increases in December, January, and February and then decreases in June, July, and August (Fig. 2). In other regions such as the Pacific coast of northern South America, and other regions centered over Uruguay and Patagonia, the same year-round precipitation change is expected.

Throughout the 20th century, significant increases in precipitation were observed in southern Brazil, Paraguay, Uruguay, northeast Argentina, and northwest Peru and Ecuador. Conversely, a declining trend in precipitation amounts was observed for southern Chile, southwest Argentina, and southern Peru. ${ }^{5}$

During the past three decades, South America has been subjected to climate-related impacts as a result of increased El Niño weather phenomena. Two extremely intense episodes of the E1 Niño phenomenon (1982-1983 and 19971998) and other severe climate extremes occurred during this period, contributing greatly to the heightened vulnerability of human systems to natural disasters (floods, drought, landslides, etc.). The frequency of weather and climatic 

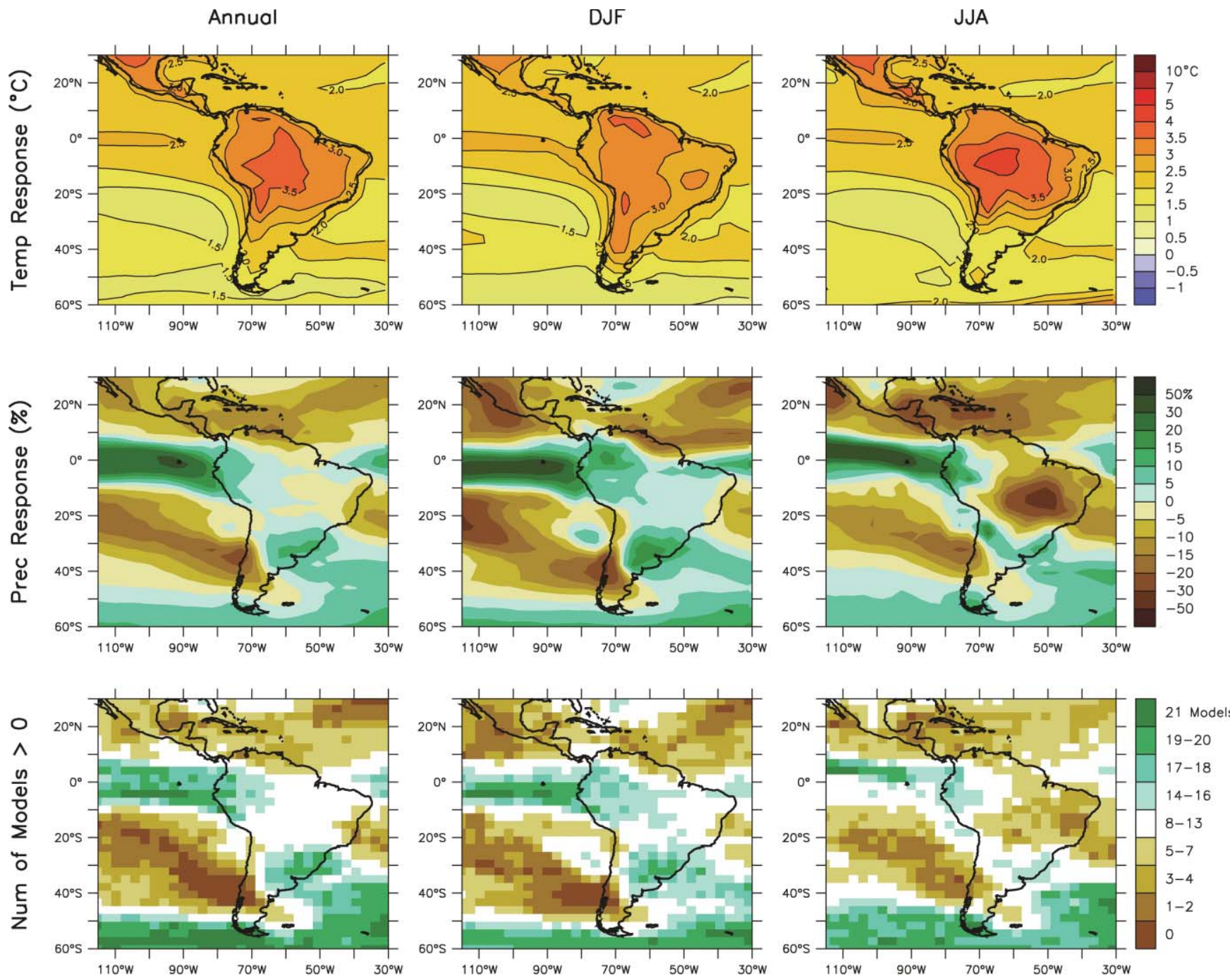

Figure 2. Temperature and precipitation changes over Central and South America from the MMD-A1B simulations. Top row: Annual mean, DecemberFebruary (DJF) and June-August period (JJA) temperature change between 1980-1999 and 2080-2099, averaged over 21 models. Middle row: same as top, but for fractional change in precipitation. Bottom row: number of models out of 21 that project increases in precipitation. Reproduced with permission from Christensen et al. ${ }^{5}$

extremes in South America is likely to increase in the future. ${ }^{5}$ Some models anticipate extremely wet seasons whereas others show the opposite tendency. However, models agree with the projections of more intense precipitation events per year over large parts of southeastern South America and weaker precipitation extremes over the coasts of northeast Brazil.

At the expense of forests, the area planted to soybeans in South America, projected to be one of the main drivers of future land-use change, is expected to almost double by the year 2020. This massive deforestation will have negative impacts on the biological diversity and ecosystem composition of South America. Such change will likely have important implications for regional and local climate conditions.

Increased pressure on rangeland resources is expected in the future as a consequence of land-use intensification, with significant environmental implications. Patagonia is an example; the introduction of unsustainable sheep stocking rates, along with inappropriate management, has resulted in major changes in rangeland composition, primary productivity, and the extent of desertification. This degradation is causing the loss of approximately $1,000 \mathrm{~km}^{2}(247,100$ acres) of productive rangeland each year. Overall, $35 \%$ of the area's rangelands, primarily grass-shrub steppes, have been transformed into deserts. As a result, the number of sheep decreased by $30 \%$ between 1960 and 1988-representing a total loss of about US $\$ 260$ million during this period. ${ }^{6}$

\section{Implications of Climate Change for Rangeland Resources}

Climate changes are already affecting South American rangelands. Reported impacts associated with heavy precipitation events are increases in flooding, stream flows, 
landslides, and erosion, which can affect rangeland productivity. Forage production is expected to increase with an increase in precipitation. However, this pattern likely only holds under climatic conditions where the frequency of extreme storm events does not increase, i.e., higherintensity storm events associated with climate change could damage soils and range plants that depend upon them. For the Pampas region, an increase in annual precipitation led to increases in pasture productivity by $7 \%$ in Argentina and Uruguay during the past decade, ${ }^{7}$ along with increases in soybean, maize, wheat, and sunflower production. Pasture forage increases could, in turn, have a positive effect on livestock production due to the linear relationship between primary production and herbivore biomass. ${ }^{4}$ Conversely, mean precipitation decreases are expected for several South American rangelands. In these cases the opposite could be true, assuming that the linear relationship between mean annual precipitation and livestock biomass holds.

Predicted increases in the frequency and intensity of extreme events are expected to affect effective precipitation and primary production. Increases in the frequency and intensity of extreme events, where dry years might be more common and even more pronounced, are expected to cause higher production variability between years, with negative consequences in forage production and for the stability of livestock production. Field manipulative experiments help to understand the ecological consequences of climate changes. For example, in the Patagonian steppe, manipulative experiments showed that a past high-intensity drought $(80 \%$ average rainfall reduction) caused a $40 \%$ reduction in aboveground primary productivity (compared with sites that had not experienced drought) during the next year, even when that year had higher-than-average annual precipitation. ${ }^{8}$

Temperature can directly impact animal production. Heat waves in central Argentina have led to reductions in milk production in Holando Argentino (Argentine Holstein) dairy cattle, and the animals were not able to completely recover after these events. As a consequence, cattle and dairy productivity is expected to decline in response to increasing temperature. In addition, temperate grasslands and dependent animal production systems are vulnerable to drought. Therefore, livestock production could be negatively affected by higher temperatures or a decline in soil water availability. However, experience has shown that extreme events, such as large-scale floods or drought-erosion cycles, can pose the highest risks. ${ }^{9}$

Historically, South American consumption of animal products (meat and dairy) was greater than other developing countries and is predicted to increase even further. The annual per capita demand for meat products is projected to rise to $64.3 \mathrm{~kg}$ (140 pounds) per person in 2020. Demand already is very close to supply and this is also true for milk. This could lead to more intensive agricultural systems in the future, a transition that is already underway.

\section{Management Responses to Climate Change}

As we described above, climate change will negatively affect rangelands in two ways: reducing average water availability and increasing its variability. In general, it would be easier to manage for consistently lower water availability than for extreme drought because of the difficulty in predicting and deploying responses to these events. Extreme droughts have short-term consequences resulting from reduced production and the longer-term effect of overgrazing. In some cases, the combination of drought and overgrazing has resulted in irreversible damage when ecosystems transitioned to another state.

We suggest that a good management tool would be the development of region-specific Rangeland Alarm Systems (RAS). These systems would alert ranchers, land managers, and policy makers of impending droughts and would encourage them to act promptly to protect rangelands and dependent livestock operations. RASs are conceptually related to alarm systems developed for fruit growers, alerting them to insect plagues and informing farmers about the types and timing of the use of pesticides. Climatic conditions, mathematical models, and insect counts are the basis for plague alarm systems. RASs should be a combination of quantitative understanding and monitoring of production systems, medium term meteorological forecasts, predictive modeling, and a communication network. Currently, medium-term weather forecasts are available and certainly they will improve with time. Ecological models would combine medium-term forecasts of rainfall amount and seasonality to forecast forage production. These models would be easier to develop in regions where the rainy season and the growing season are out of synchrony, such as the annual grasslands of California or the steppes of Patagonia. The occurrence of the bulk of precipitation a few months before the growing season starts provides the opportunity to forecast forage shortages a few months ahead of their occurrence. The lead time that the alarm system provides would allow ranchers and land managers to get ready and implement a series of response options. However, the use of advanced technologies to better predict impending droughts and forage shortages is only one half of the management conundrum. The advanced knowledge must be accompanied by the implementation of management responses. History has shown that the former is not necessarily accompanied by the latter.

Major response options to drought are associated with alleviating forage and water shortage. Basically, there are two types of approaches to the problem: reduce stocking rates or increase forage and water supplies. Managers who have to reduce stocking rates would benefit from the use of RAS because they will be able to sell their animals before prices drop as a result of the drought. RAS would smooth the economic ups and downs of farm income by providing lead time to reduce stocking rates. An alternative approach to reducing stocking rates is to secure additional forage. 
Specifics as to where to obtain additional forage depend on the region and the ranch. In some cases, managers might need to buy forage or grain from other ranches or from other regions. In another case, they can save paddocks with stockpiled forage to be consumed during the drought.

Governments can contribute by developing regionspecific RAS. Secondly, they could develop communication networks of RAS predictions using regional television, radio, and other media to reach producers, extension service professionals, and local governments. Third, governments can facilitate the implementation of response options by providing loans for ranchers to purchase additional forage or grain, although this supplement-based approach could contribute to the problem if grazing pressure on rangelands is not reduced. In some regions, governments might reduce tax burdens during drought periods to alleviate part of the economic consequences of reduced production.

\section{Acknowledgments}

We thank Joel Brown for the invitation to write this manuscript, which led us to think about rangelands from a different point of view. Institutional support was provided by Instituto de Investigaciones Fisiológicas y Ecológicas Vinculades a la Agricultura, Consejo Nacional de Investigaciones Científicas y Técnicas, University of Buenos Aires, and Brown University. We are grateful to Hernán Dieguez, who provided assistance with the South America Rangeland map.

\section{References}

1. Intergovernmental Panel on Climate Change. 1996. Technical summary. In J. T. Houghton, L. G. Meira Filho, B. A. Callender, N. Harris, A. Kattenberg, and K. Maskell [EDs.]. Climate change 1995: the science of climate change. Contribution of Working Group II to the Second Assessment Report of the Intergovernmental Panel on Climate Change. Cambridge, United Kingdom, and New York, NY, USA: Cambridge University Press. p. 572.

2. McNaughton, S. J., O. E. Sala, and M. Oesterheld. 1993. Comparative ecology of African and South American arid to subhumid ecosystems. In P. Goldblatt [ED.]. Biological relationships between Africa and South America. New Haven, CT, USA: Yale University Press. p. 548-567.

3. McNaughton, S. J., M. Oesterheld, D. A. Frank, and K. J. Williams. 1989. Ecosystem-level patterns of primary productivity and herbivory in terrestrial habitats. Nature 341: 142-144.

4. Oesterheld, M., O. E. Sala, and S. J. McNaughton. 1992. Effect of animal husbandry on herbivore-carrying capacity at a regional scale. Nature 356:234-236.

5. Christensen, J. H., B. Hewitson, A. Busuioc, A. Chen, X. Gao, I. Held, R. Jones, R. K. Kolli, W.-T. Kwon, R. Laprise, V. Magaña Rueda, L. Mearns, C. G. Menéndez, J. Räisänen, A. Rinke, A. Sarr, and P. Whetton. 2007. Regional Climate Projections. In S. Solomon, D. Qin, M.
Manning, Z. Chen, M. Marquis, K. B. Averyt, M. Tignor, and H. L. Miller [eDs.]. Climate change 2007: the physical science basis. Contribution of Working Group I to the Fourth Assessment Report of the Intergovernmental Panel on Climate Change. Cambridge, United Kingdom, and New York, NY, USA: Cambridge University Press. p. 846-940.

6. Sala, O. E., and J. M. Paruelo. 1997. Ecosystem services in grasslands. In G. C. Daily [ED.]. Nature's services: societal dependence on natural ecosystems. Washington, DC, USA: Island Press. p. 237-252.

7. Gimenez, A. 2006. Climate change and variability in the mixed crop/livestock production systems of the Argentinean, Brazilian, and Uruguayan Pampas. Final Report, AIACC Project LA27, 70 pp. Available at: http://www.aiaccproject. org/. IPCC DDC, 2003, 1032 p. Accessed 3 December 2008.

8. Yahdjian, L., and O. E. Sala. 2006. Vegetation structure constrains primary production response to water availability in the Patagonian steppe. Ecology 87(4):952-962.

9. Soriano, A. 1992. Present conditions in the Patagonian rangelands, in relation to potential impacts of a global climate change. Intergovernmental Panel on Climate Change. Response Strategies. Canberra, Australia: Working Group, WMU, UNEP. p. 104-116.

10. Olson, D. M., E. Dinerstein, E. D. Wikramanayake, N. D. Burgess, G. V. N. Powell, E. C. Underwood, J. A. D’Amico, H. E. Strand, J. C. Morrison, C. J. Loucks, T. F. Allnutt, J. F. Lamoreux, T. H. Ricketts, I. Itoua, W. W. Wettengel, Y. Kura, P. Hedao, and K. Kassem. 2001. Terrestrial ecoregions of the world: a new map of life on Earth. BioScience 51:933-938.

11. Eva, H. D., E. E. D. Miranda, C. M. D. Bella, V. Gond, O. Huber, M. Sgrenzaroli, S. Jones, A. Coutinho, A. Dorado, M. Guimarães, C. Elvidge, F. Achard, A. S. Belward, E. Bartholomé, A. Baraldi, G. D. Grandi, P. Vogt, S. Fritz, and A. Hartley. 2002. A vegetation map of South America. Environment and quality of life series. 2002 EUR 20159 EN. Luxembourg: Office for Official Publications of the European Communities, 2002. 34 p.

Authors are Research Scientist, Institute for Agricultural Plant Physiology and Ecology (Instituto de Investigaciones Fisiológicas y Ecológicas Vinculadas a la Agricultura), Argentine National Research Council (Consejo Nacional de Investigaciones Cientificas y Técnicas [CONICET]), and the Department of Ecology, School of Agronomy, University of Buenos Aires, Av. San Martin 4453, C1417DSE, Buenos Aires, Argentina, yahdjian@iferva. edu.ar (Yabdjian); and Professor, Department of Ecology and Evolutionary Biology and Director of the Environmental Change Initiative, Brown University, Box 1951, Providence, RI 02912, USA (Sala). This research was funded by the National Agency for Promotion of Science and Technology (Agencia Nacional de Promoción Cientifica y Tecnológica): PICT 11298 and PICT 32548; CONICET; and the University of Buenos Aires (Universidad de Buenos Aires). Yabdjian's participation in this study was supported by CONICET. 